\title{
Transitions in the surface energy balance during the life cycle of a monsoon season
}

\author{
T N Krishnamurti* and Mrinal K BisWas \\ Department of Meteorology, The Florida State University, Tallahassee, FL 32306, USA. \\ *e-mail: tnk@io.met.fsu.edu
}

In this observational/diagnostic study, we illustrate the time history of some important parameters of the surface energy balance during the life cycle of a single monsoon season. This chronology of the surface energy balance portrays the differential equilibrium state from the preonset phase to the withdrawal phase. This includes an analysis of the time history of base variables such as soil moisture, ground temperature, cloud cover, precipitation and humidity. This is followed by an analysis of the components of the surface energy balance where we note subtle changes in the overall balances as we proceed from one epoch of the monsoon to the next. Of interest here is the transition sequence: preonset, onset, break, revival, break, revival and withdrawal during the year 2001. Computations are all illustrated for a box over central India where the coastal effects were small, data coverage was not sparse and where the semi-arid land mass changes drastically to a lush green area. This region exhibited large changes in the components of surface energy balance. The principal results pertain to what balances the difference among the incoming short wave radiation (at the earth's surface) and the long wave radiation exhibited by the ground. That difference is balanced by a dominant sensible heat flux and the reflected short wave radiation in the preonset stage. A sudden change in the Bowen ratio going from $>1$ to $<1$ is noted soon after the onset of monsoon. Thereafter the latent heat flux from the land surface takes an important role and the sensible heat flux acquires a diminishing role. We also examine the subtle changes that occur in the components of surface energy balance between the break and the active phases. The break phases are seen to be quite different from the preonset phases. This study is aimed to illustrate the major importance of moisture and clouds in the radiative transfer computations that are central to the surface energy balance during each epoch. These sensitivities (of moisture and clouds) have major consequences for weather and climate forecasts.

\section{Introduction}

Prior to the onset of monsoon, many parts of south Asia experience semi-arid conditions from prolonged lack of rain. A major change in the land surface and atmospheric structures follow soon after the onset of the monsoon rains. Surface air temperatures drop from near $40^{\circ} \mathrm{C}$ to as low as $26^{\circ} \mathrm{C}$ and the land-atmosphere system seems to acquire a new equilibrium. In this paper, we illustrate some of these transitions that are exhibited by a number of surface energy balance parameters. We have taken central India as a point of reference because the transitions from a semi-arid land to moist green land surface are very marked as compared to the coastal onset situations and the data coverage is better over this region.

A domain of interest for this study is shown in figure (1). This is located over central India where marked changes in the soil properties and in the surface energy balance components were noted during the different epochs of monsoon activity during a single season. This domain is just north of the Vindhya Mountains and is part of the central

Keywords. Surface energy balance; onset/active/break cycle of monsoon; transition in Bowen ratio.

J. Earth Syst. Sci. 115, No. 2, April 2006, pp. 185-201

(C) Printed in India. 


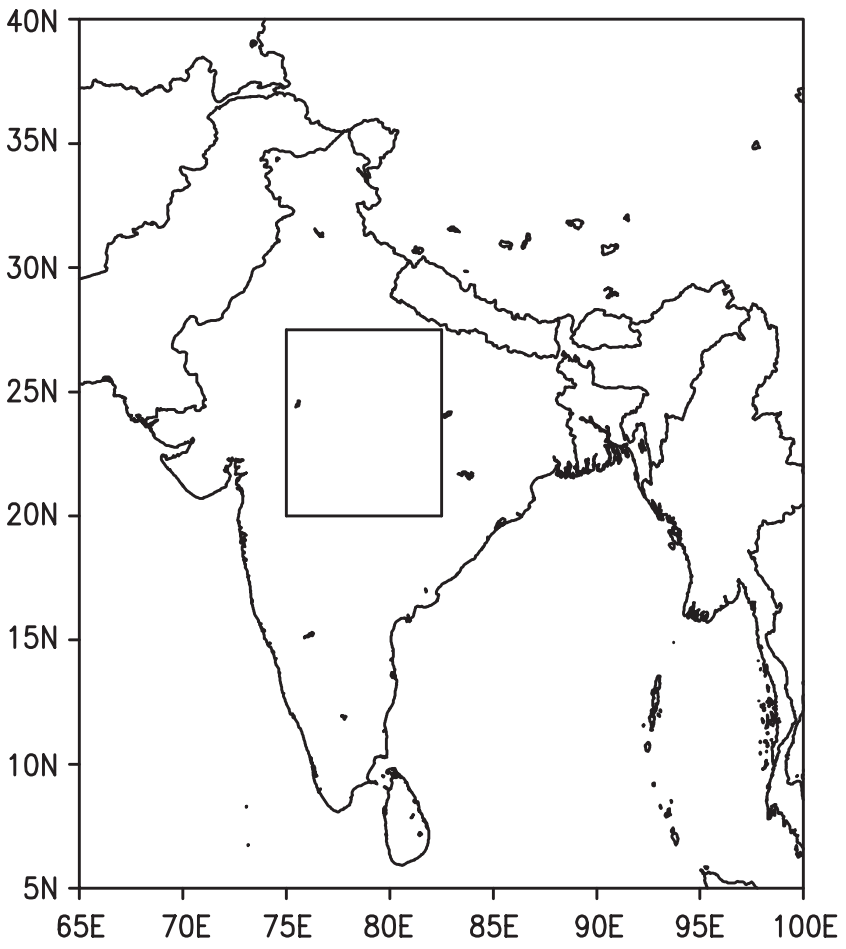

Figure 1. Selected domain for computation of surface energy balance over central India.

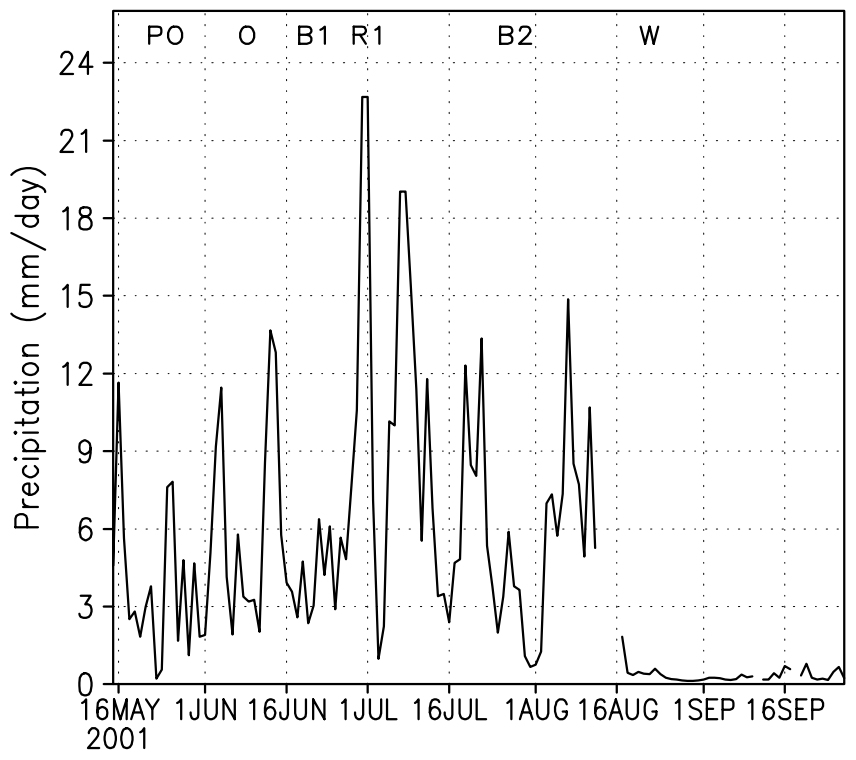

Figure 2. Daily area averaged rainfall over our domain of interest in central India (mm/day); period 15 May to 30 September 2001, these are based on TRMM satellite measurements.

plains. The area averaged daily rainfall totals for this box are shown in figure (2). The region experienced some pre-monsoon thunderstorms prior to the onset of monsoon rains in late May when the rainfall amounts were less than $3 \mathrm{~mm} /$ day, however, in general the rainfall amounts prior to the onset of monsoon were around $6 \mathrm{~mm} /$ day. These are average values, however daily extreme values have been as large as $8-12 \mathrm{~mm} /$ day. The central
India onset of rains occurred around June 13. This was in fact followed by a succession of dry and wet spells. The first heavy rain spell came in early June when the area averaged rainfall peaked at $13 \mathrm{~mm} /$ day. There were some inter-diurnal swings of rainfall totals with a break in monsoon rains in late June and in early August as well, active rains were noted in early July and during the second week of August. The withdrawal of monsoon over this box was felt quite early, i.e., in the last half of August 2001. In this study we shall designate the transitions in various quantities during the onset (around June 13) (O), the first major break (B1) in monsoon rainfall around June 23 , the revival and active spell (R1), starting around July 1, the second major break (B2) around August 1, a second revival (R2) around August 8 and an early withdrawal (W) over central India around the second half of August 2001.

The Normalized Difference of the Vegetative Index (NDVI) is a measure of the vegetation cover (list of acronyms are provided in table 1). It is calculated from reflectances measured in the visible and near infra-red channels from satellite based remote sensing. We show here how the NDVI pattern changes from a preonset to a postonset period. Figure $3(\mathrm{a}, \mathrm{b}, \mathrm{c}$ and $\mathrm{d})$ illustrates these transitions over the land surface as seen from the NDVI data sets for the year 2001. Healthy vegetation has a very high NDVI value while bare soil and rocks reflect similar to red and near-infrared and thus will have near-zero NDVI. These changes of NDVI generally show that the transitions of the land surface are quite abrupt and the atmosphere seems to arrive at a new equilibrium for its surface energy balance within a matter of several weeks. In the following section we shall provide a short account on some of the rapid changes that were felt by a number of parameters during the life cycle of a single monsoon season. The onset is followed by a few active and break spells in precipitation and culminates with the withdrawal of the monsoon rains. It is of considerable interest to examine the

Table 1. Description of the acronyms used in the text.

\begin{tabular}{ll}
\hline Acronym & \multicolumn{1}{c}{ Description } \\
\hline NDVI & Normalized Difference Vegetative Index \\
NCEP & National Center for Environment Prediction \\
NCAR & National Center for Atmospheric Research \\
OLR & Outgoing Long Wave Radiation \\
DLWRF & Long Wave Radiation down at Surface \\
ULWRF & Upward Long Wave Radiation at Surface \\
USWRF & Upward Short Wave Radiation at Surface \\
LHTFLX & Latent Heat Flux at Surface \\
SHTFLX & Sensible Heat Flux Surface \\
DSWRF & Downward Short Wave Radiation at Surface
\end{tabular}




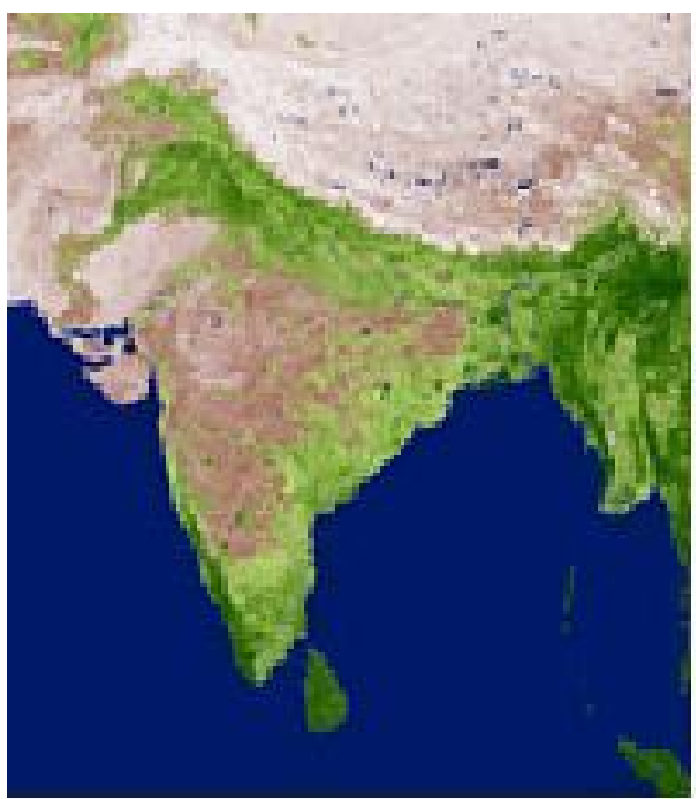

(a)

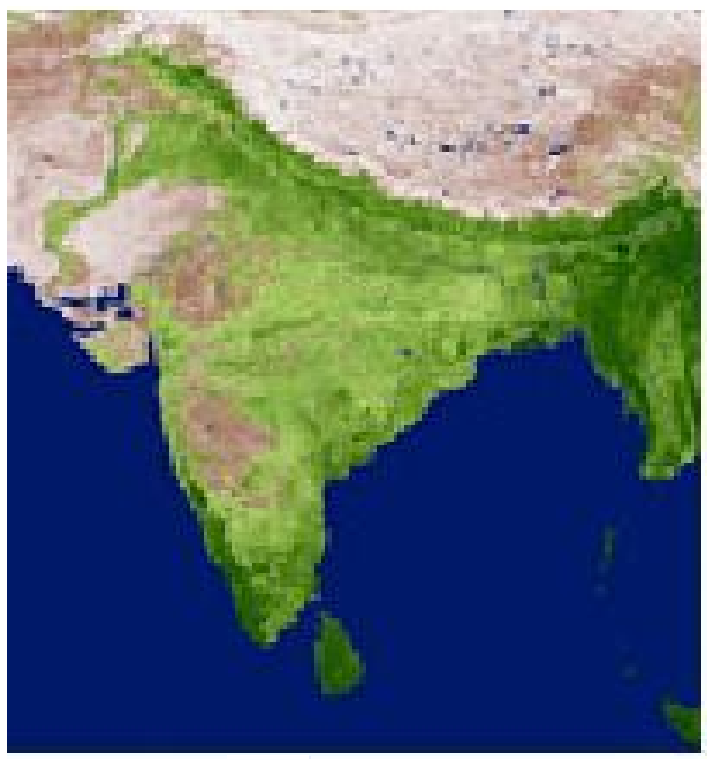

(c)
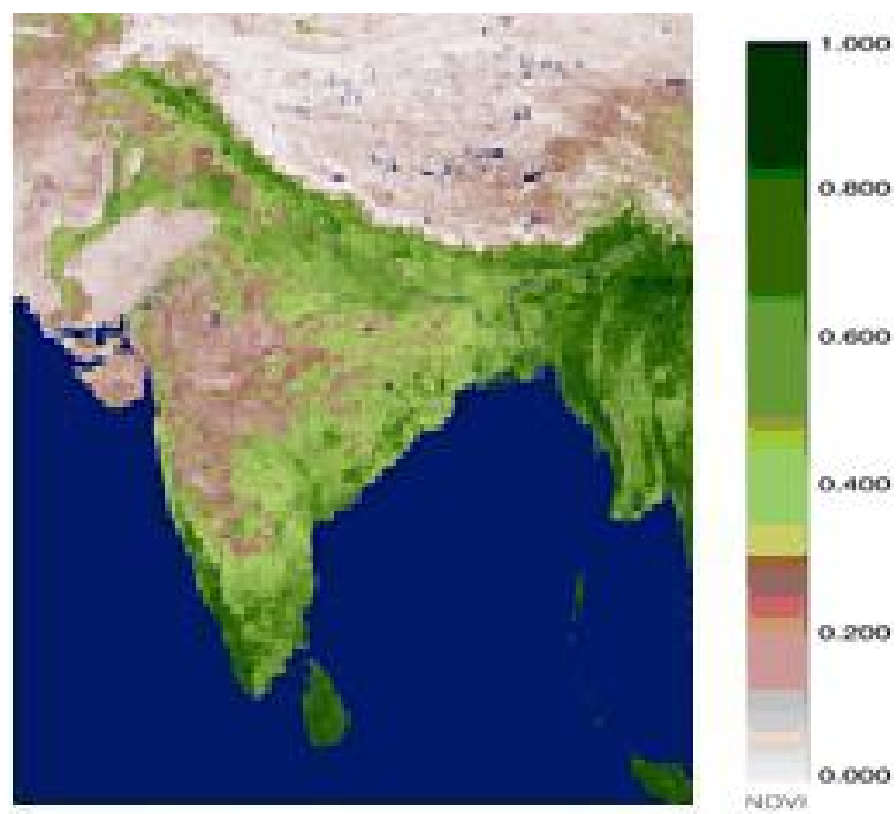

(b)

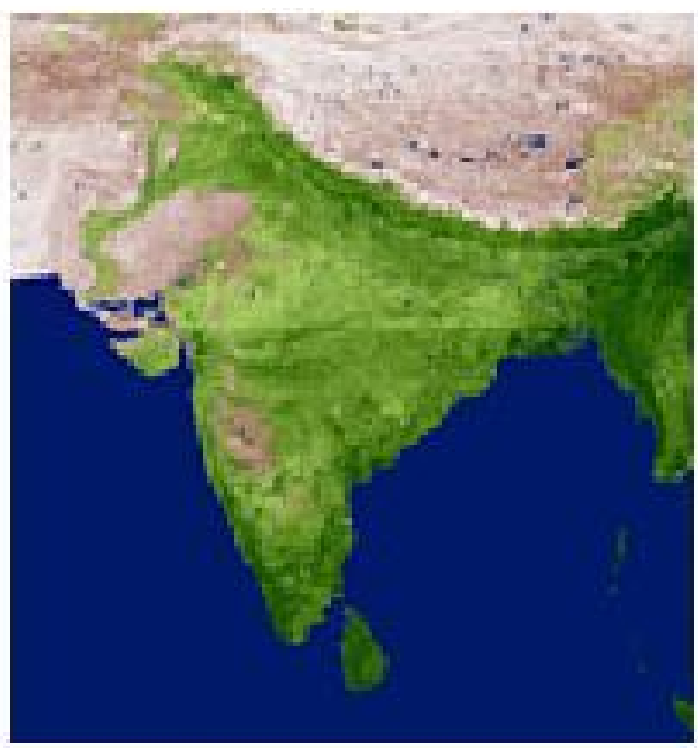

(d)

Figure 3. 16-day average filled NDVI over India during (a) April 23 to May 8, 2001; (b) May 9 to May 24, 2001; (c) June 11 to June 26, 2001; (d) June 27 to July 11, 2001; these are based on MODIS-atmosphere.

changes in the surface energy balance parameters between such dry and wet spells of a single season. This is a very dramatic change of scenario that deserves detailed studies since these are essential elements for seasonal climate forecasts.

\section{Data sets and methodology}

The data sets used for this study include the NCEP/NCAR reanalysis (Kalnay et al 1996). The daily outgoing long wave radiation data sets were extracted from NOAA. Rainfall estimates were based on the TRMM satellite's microwave radiometer algorithm (Kumerow et al 1998).

No ground truth comparisons for most of the surface fluxes were available and hence these are calculated here indirectly mostly from the assimilated data sets and are sometimes tuned to ensure net energy balance (Kistler et al 2001) from the NCEP/NCAR reanalysis.

In the reanalysis the radiative transfer includes: Short wave Rayleigh scattering and absorption in ultraviolet (wavelengths $<0.35$ microns) and 
visible (wavelengths $0.5-0.7$ microns) spectral bands by ozone, and in the near-infrared (wavelengths $0.7-4.0$ microns) by water vapor follows the method of Lacis and Hansen (1974). Absorption by carbon dioxide is after Sasamori et al (1972). Pressure corrections and multiple reflections between clouds and the surface are treated. Long wave radiation follows the simplified exchange method of Fels and Schwarzkopf (1975) and Schwarzkopf and Fels (1991), with calculation over spectral bands associated with carbon dioxide, water vapor, and ozone. Schwarzkopf and Fels (1985) transmission coefficients for carbon dioxide, a Roberts et al (1976) water vapor continuum, and the effects of water vapor-carbon dioxide overlap and of a Voigt line-shape correction are included. The Rodgers (1968) formulation is adopted for ozone absorption. Cloud radiative properties for short wave (reflectance, absorptance) and long wave (emissivity) are obtained from cloud thickness, cloud layer temperature, and cloud layer moisture in a manner similar to Hashvardhan et al (1989). Independent cloud layered masses (separated by one clear layer) are randomly overlapped in the vertical direction. Vertically contiguous anvil cirrus and lower convective cloud is also randomly overlapped.

The surface flux computations in the reanalysis were based on the following: Surface solar absorption is determined from the surface albedos, and long wave emission from the Planck equation with emissivity of 1.0. The lowest model layer is assumed to be the surface layer $($ sigma $=0.995)$ and apply the Monin-Obukhov similarity profile relationship to obtain the surface stress and sensible and latent heat fluxes. The formulation was based on Miyakoda and Sirutis (1986) and has been modified by $\mathrm{P}$ Long in the very stable and very unstable situations. Bulk aerodynamic formula is used to obtain the fluxes once the turbulent exchange coefficients have to be obtained. Roughness length over ocean is updated with a Charnock formula after surface stress has been obtained. Land surface evaporation is comprised of three components: direct evaporation from the soil and from the canopy, and transpiration from the vegetation. The formulation follows Pan and Mahrt (1987).

This analysis includes a land surface module that has the following ingredients: soil temperature and soil volumetric water content are computed in two layers at depths 0.1 and 1.0 meters by a fully implicit time integration scheme (Pan and Mahrt 1987). Heat capacity, thermal and hydraulic diffusivity and hydraulic conductivity coefficients are strong functions of the soil moisture content. The vegetation canopy is allowed to intercept precipitation and re-evaporation while runoff from the surface and drainage from the bottom layer are also calculated.

\section{Transition in parameters}

We shall next illustrate some variations in some of the salient surface parameters.

\subsection{Soil temperature}

This product is derived from the surface energy balance data of the reanalysis dataset. Figure (4) illustrates the soil temperature for the top $10 \mathrm{cms}$. As to be expected the soil temperatures prior to the onset has high values between 36 and $40^{\circ} \mathrm{C}$. These higher values were seen over many places of central India. Subsequent to the onset, top soil temperatures drop to values between 28 and $30^{\circ} \mathrm{C}$ (figure 1). This near $10^{\circ} \mathrm{C}$ drop in surface temperature clearly results in a new thermodynamical equilibrium state subsequent to the onset of monsoon rains. The long wave radiations from the earth's surface reduces by roughly $10 \%$ after the onset with increased cloud cover and moisture content, the net absorbed long wave radiation by the atmosphere increases after the onset, these are also factors that contribute to the maintenance of the upper tropospheric warm core of the monsoon. During breaks in monsoon rains, the soil temperature increases to around $29^{\circ} \mathrm{C}$. The disturbance passage over the selected computational box can be illustrated for a time history of the meridional wind $(v)$ at the $850 \mathrm{hPa}$ level. We selected a small sub-area (2.5 latitude/longitude) at the

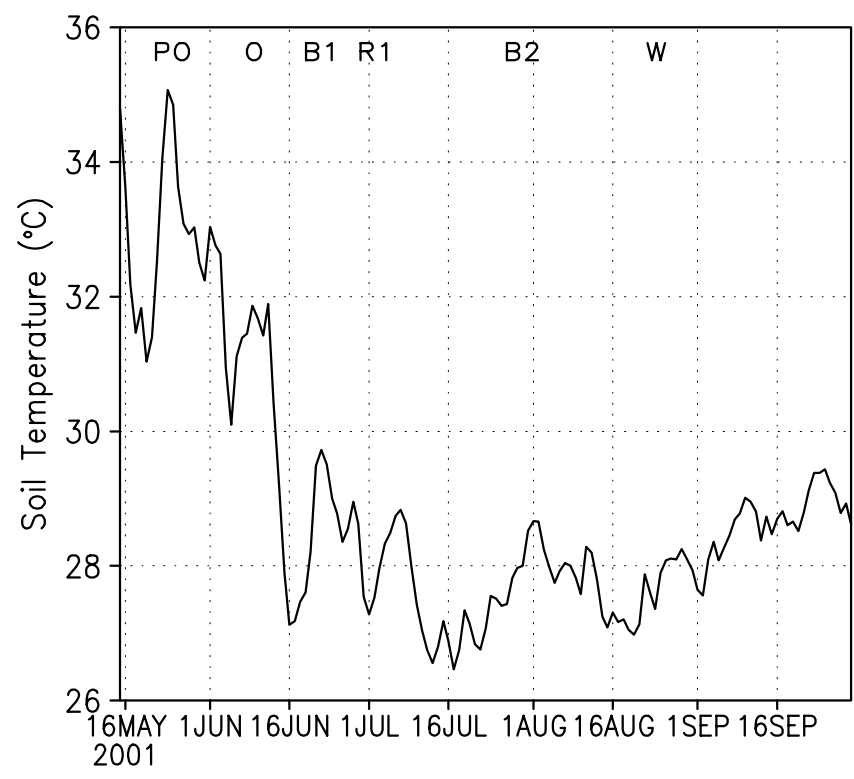

Figure 4. Daily soil temperature $(0-10 \mathrm{~cm}$ down $)$ in ${ }^{\circ} \mathrm{C}$, period 15 May to 30 September 2001. 


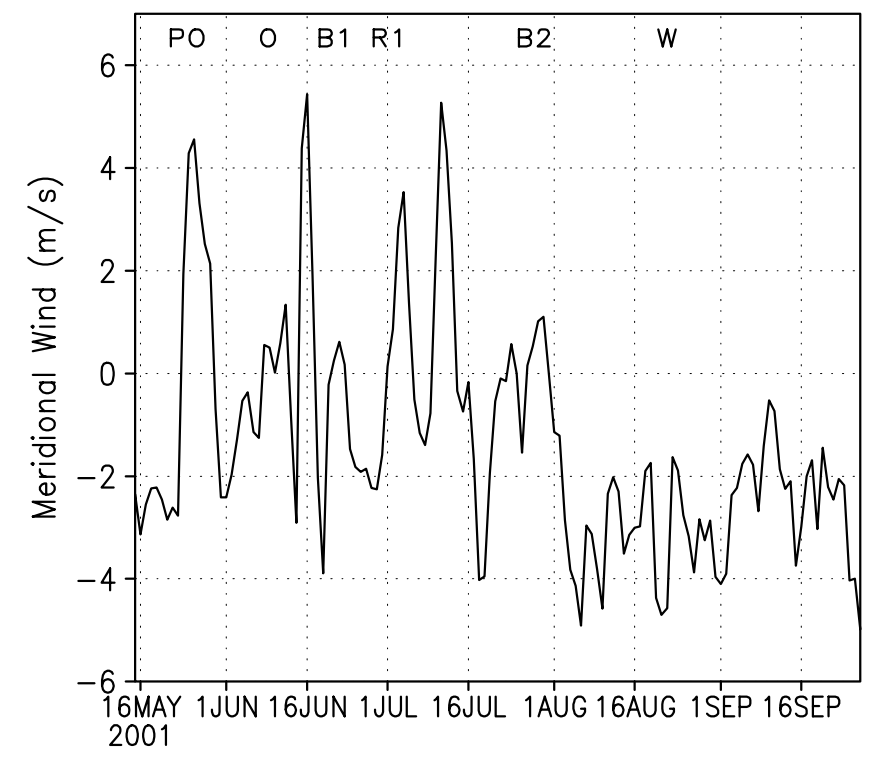

Figure 5. Daily meridional wind averaged over $2.5^{\circ}$ lat./lon. in the center of figure $1\left(\mathrm{~ms}^{-1}\right)$, period 15 May to 30 September 2001.

center of figure (1) and the daily averaged value of the $v$ component $\left(\mathrm{ms}^{-1}\right)$ is shown in figure (5). This carries roughly 22 oscillations over a period of 138 days. That accounts roughly for a 6-day passage of disturbances. Among these were 7 large amplitude oscillations carrying change of sign of the $v$ component, i.e., implying passage of monsoon depressions. We verified several of these from Thapliyal et al (2002) and from a visual inspection of maps. The other oscillations denote monsoon lows and distant (outside of the box of figure 1) disturbance passages. The fluctuations in the soil temperature are within a few ${ }^{\circ} \mathrm{C}$ between active and break spells. The rise of soil temperature is somewhat gradual as the withdrawal of monsoon occurs, the soil temperature increases to around $30^{\circ} \mathrm{C}$ by the end of September.

\subsection{Soil moisture}

The soil moisture, we present here, is not based on direct observations. This is in fact a reanalysis based product hence the values we present here are model dependent (figure 6). The main purpose of this presentation is to illustrate the major transitions and the retentivity of the soil moisture over the monsoon season across the life cycle of a single monsoon season. In the pre-monsoon semi-arid period the values of volumetric soil moisture are as low as 0.15 . The big change in soil moisture starts soon after the onset of monsoon rains and the value gradually rises to almost 0.3 by one week of heavy rains. Thereafter the values tend to maintain themselves at the values around 0.36. During a break in monsoon, that lasts for periods of the

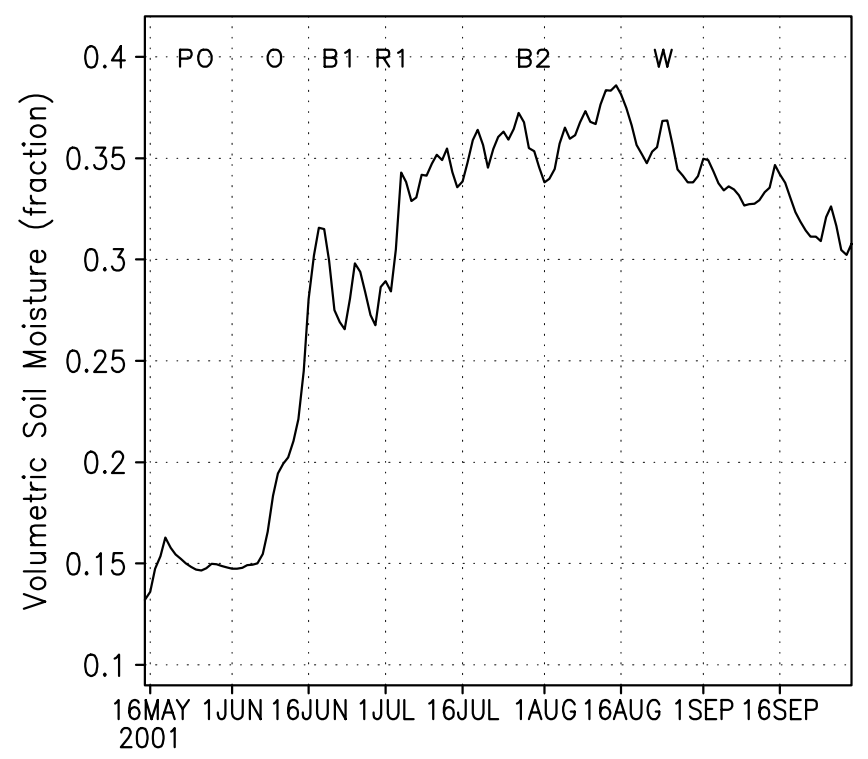

Figure 6. Daily volumetric soil moisture (fraction), period 15 May to 30 September 2001.

order of a week, soil moisture shows a slow gradual decline but does not diminish to the preonset values because some rains continues to fall even during these break spells. The revival of monsoon after the break tends to quickly elevate the soil moisture values back to around 0.36 . This shows that a high degree of soil moisture is retained once an onset has occurred, after the withdrawal of monsoon rains over central India in late August values close to 0.3 were still retained during most of September.

\subsection{Surface evaporation}

Surface evaporation at several central India sites increases from roughly $1 \mathrm{~mm} /$ day to 4 to $5 \mathrm{~mm}$ /day after the onset of monsoon rains (figure 7). Prior to the onset, the land surface is hot and the dryness of air contributes to some evaporation, but this preonset semi-arid state seems to sustain evaporation only of the order of $1 \mathrm{~mm} /$ day. Subsequent to the onset the land surface temperature drops to near $30^{\circ} \mathrm{C}$, the air is somewhat more moist but the evaporation under stronger wind conditions (winds $\approx 10 \mathrm{~ms}^{-1}$ ) gets almost 4 to 5 folds larger. Passages of monsoon lows and the associated cloud cover seem to modulate the evaporation rate over land on a time scale of roughly 5 days. When we consider an averaged moisture budget over a domain such as the size of figure (1), we find that evaporation rates of the order of $5 \mathrm{~mm}$ /day correspond to $20 \%$ of recycling of the area averaged precipitation. Those estimates can be larger locally. (This is based on local moisture budget computations. It is a detailed topic and will be discussed in a separate paper.) Most of the moisture for the 


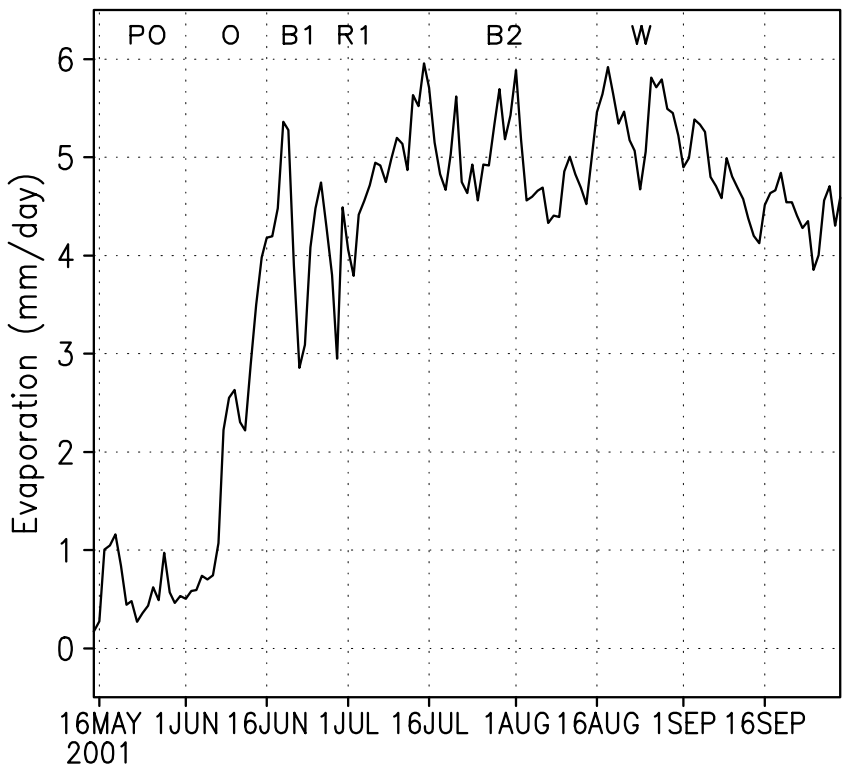

Figure 7. Daily surface evaporation (mm/day), period 15 May to 30 September 2001.

observed rainfall however comes from horizontal transports and related convergence of flux of moisture from the Arabian Sea and the Bay of Bengal. Soil moisture over this region (after the onset of rain), does provide a means to sustain buoyancy for newly forming clouds those in turn seem to draw upon the moisture laterally by horizontal advective processes. Enhanced soil moisture does not provide a moisture source to account the enhanced rains but it helps the organization of new clouds those in turn draw the moisture from the neighboring ocean basins. Evaporation values gradually drop from around $5 \mathrm{~mm}$ /day to $4 \mathrm{~mm}$ /day during the withdrawal phase after August 20th.

\subsection{Depth of moist layer}

The components of surface radiation seem to be more sensitive to the water vapor and clouds hence the depth of moist layer is an important element. The arrival of the southwesterly wet monsoon current from the Arabian Sea elevates the depth of the moist layer dramatically subsequent to the onset of monsoon. That can be monitored from the height of the $1 \mathrm{~g} / \mathrm{kg}$ specific humidity surface (figure 8). Using the reanalysis data, it was possible to extract that surface on a daily basis and examine its time history at several latitudes during the summer monsoon of 2001. We can see a clear change in the depth and rate of rise of the moist layer between May and July. The onset period is clearly distinguished with an abrupt rise of the depth of the moist layer. The depth of the moist layer rises from $780 \mathrm{hPa}$ level to the $710 \mathrm{hPa}$ level during the onset and to $690 \mathrm{hPa}$ subsequent to the

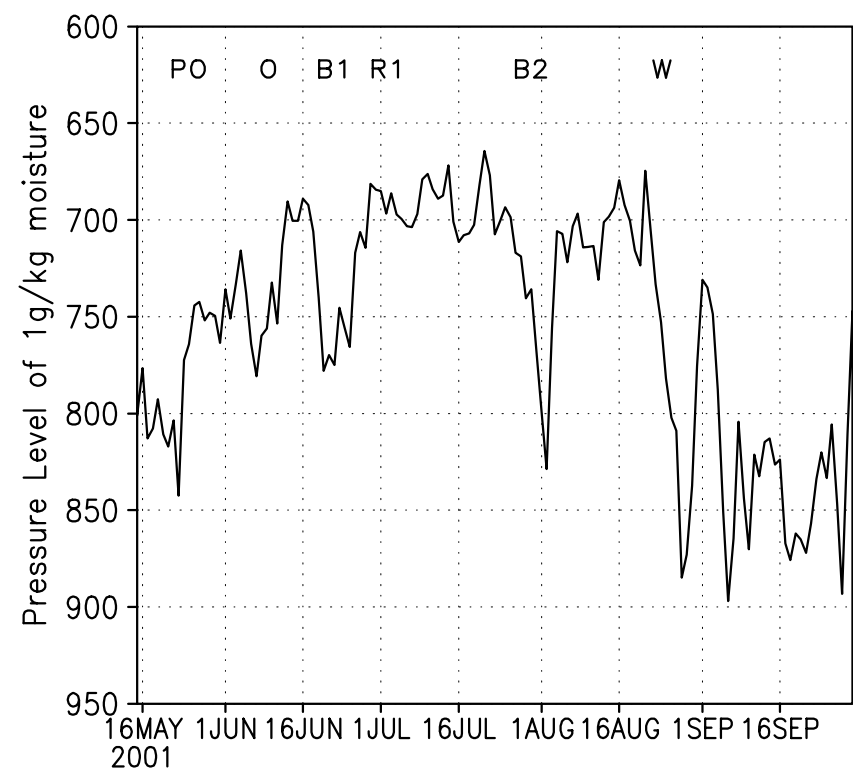

Figure 8. Daily depth of $1 \mathrm{~g} / \mathrm{kg}$ moist layer along the vertical (hPa), period 15 May to 30 September 2001.

onset around June 13. Simon and Joshi (1994) also noted an increase in scale height of water vapor and tropospheric moisture before and during the onset. This increased depth of moist layer has important implications for the absorbed net radiation by the troposphere. During the breaks B1 the depth of moist layer reduces to the preonset values, i.e., near $850 \mathrm{hPa}$. Tropospheric sinking motion influences the depth considerably during the breaks. During the active spells, this depth again rises to almost $700 \mathrm{hPa}$ level. The break B2 in August sees the bigger drop in the depth of moist layer and the $1 \mathrm{~g} / \mathrm{kg}$ isopleth fluctuates around the $850 \mathrm{hPa}$ level after the withdrawal of the monsoon.

\subsection{Vertically integrated moisture transport vector fields}

Chen et al (1988) have addressed the moisture transport vectors of the Asian monsoon in the context of divergent and rotational motions. The product of the mass transport vectors $\vec{V}$ and the specific humidity $q$ can be integrated through the depth of the troposphere to map the moisture transport vectors $\overrightarrow{V q}$. The moisture transport vectors during different epochs of the summer monsoon over India during 2001 show a textbook case of chronology of events (figure 9). In the preonset (PO) period (around May 22) most of the strong transports of moisture are noted south of $5^{\circ} \mathrm{N}$. Dry air from the northwest enters most of India during this preonset phase. During the onset phase (around June 13) the west to east swath of moisture transport has reached roughly $15^{\circ} \mathrm{N}$, moisture over the northern Bay of Bengal 

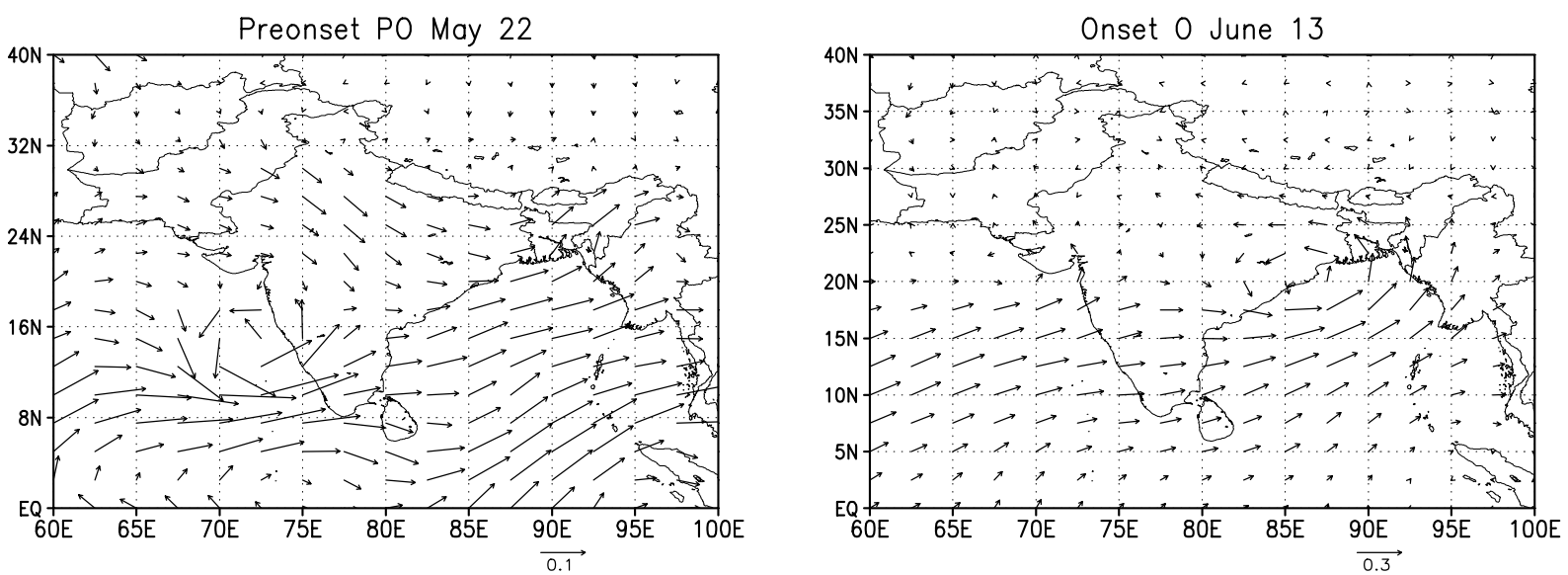

First Break B1 June 26
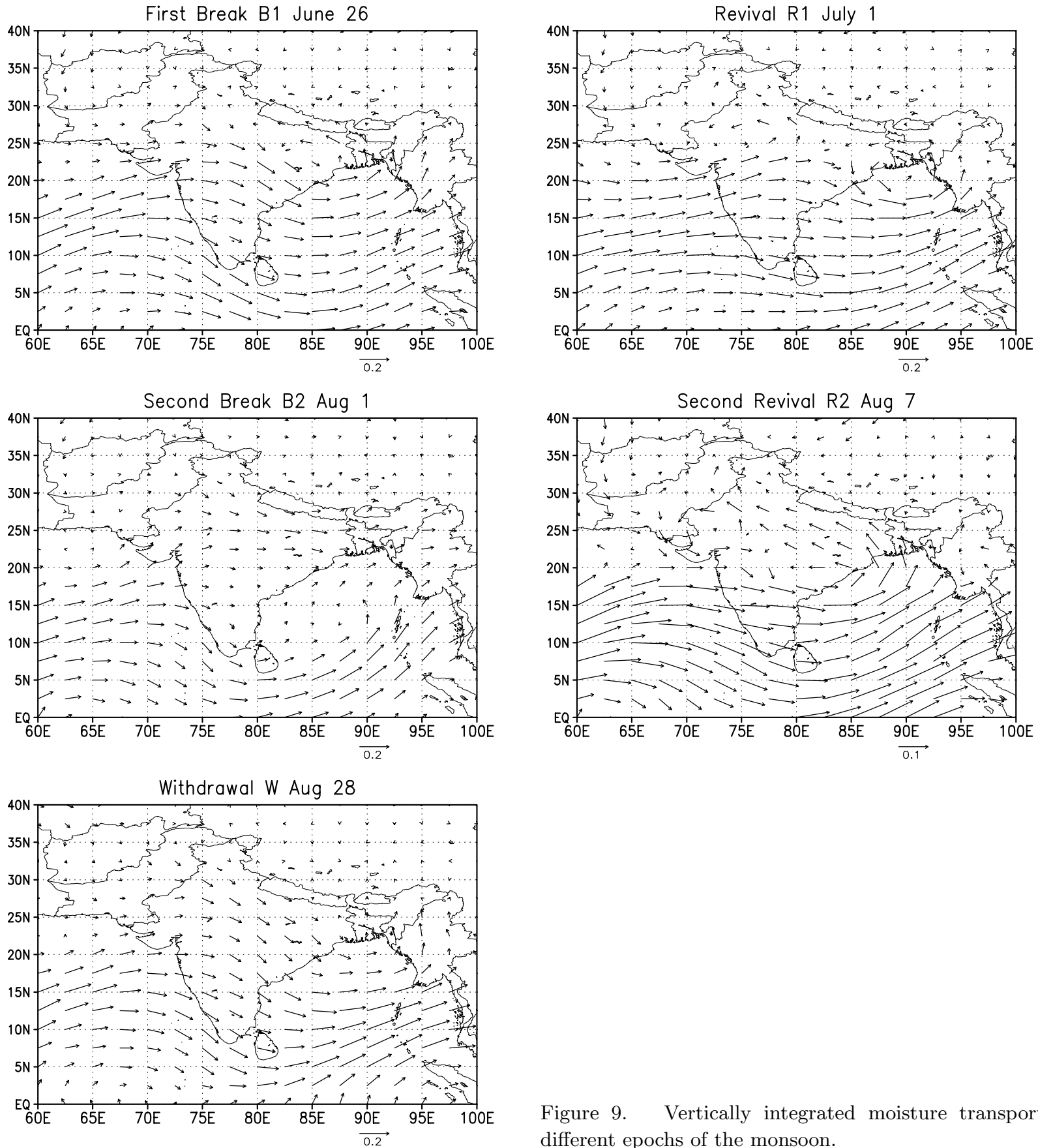

Figure 9. Vertically integrated moisture transports during different epochs of the monsoon. 
shows a cyclonic influence bringing in moisture into the inland regions. By the time of the first break (B1) around June 26, deep moist westerlies bringing Arabian Sea air have already penetrated to roughly $22^{\circ} \mathrm{N}$, however the northerly component of wind over northern India with an extended trough over the Bay of Bengal is characterized by downward motion over most of northern India. That picture of northerly reverts by around July 3 back to a broad westerly moist current from the Arabian Sea as the monsoon revives (R1). The trough in the Bay weakens and moves much farther south. A strong spectacular break (B2) near August 1 shows marked changes in the moisture transport vectors. The deep moist current has almost moved south of India, the flows over India are characterized by dry air flows from the northwest. It is interesting to see a rapid transition to a second revival phase (R2) (August 7) when the deep moist current again penetrates to roughly $17^{\circ} \mathrm{N}$ over India and an active monsoon depression brings in moisture between $20^{\circ} \mathrm{N}$ and $30^{\circ} \mathrm{N}$ from the Bay of Bengal. This was a period of very heavy monsoon rains over the northern Gangetic plains. The picture during the withdrawal shows a northward penetration of the moist monsoon only through roughly $15^{\circ} \mathrm{N}$. The big change during this phase is clearly the extent of dry northwesterly flows over most of northern India (including the computational box over central India (figure 1). These dry northwesterlies penetrate across India through the central Bay of Bengal. These are characteristic features of the withdrawal of the monsoon.

\subsection{Total precipitable water}

The total precipitable water is computed from NCEP reanalysis data sets (figure 10 ). The monsoon onset sees major transitions in the water holdings over the land surface (the soil moisture), in the atmosphere (the total precipitable water), depth of the moist layer, precipitation and cloud cover all undergo major transitions. In the semi-arid preonset stage, the precipitable water is around $35 \mathrm{~kg} / \mathrm{m}^{2}$ and increases to as high as $55 \mathrm{~kg} / \mathrm{m}^{2}$ subsequent to the onset. We do note some marked fluctuation in the total precipitable water on the quasi-biweekly time scales, which is the time scale of the monsoon depressions, the same as contrasted from monsoon lows that have period around 5 days. The passage of such monsoon depressions bring in dry descending air from the north that seem to moderate the precipitable water by as much as 7 to $10 \mathrm{~kg} / \mathrm{m}^{2}$. Precipitable water of the monsoon is made up of high water content through a finite depth (as much as 3 to $5 \mathrm{~km}$ ) of the atmosphere.

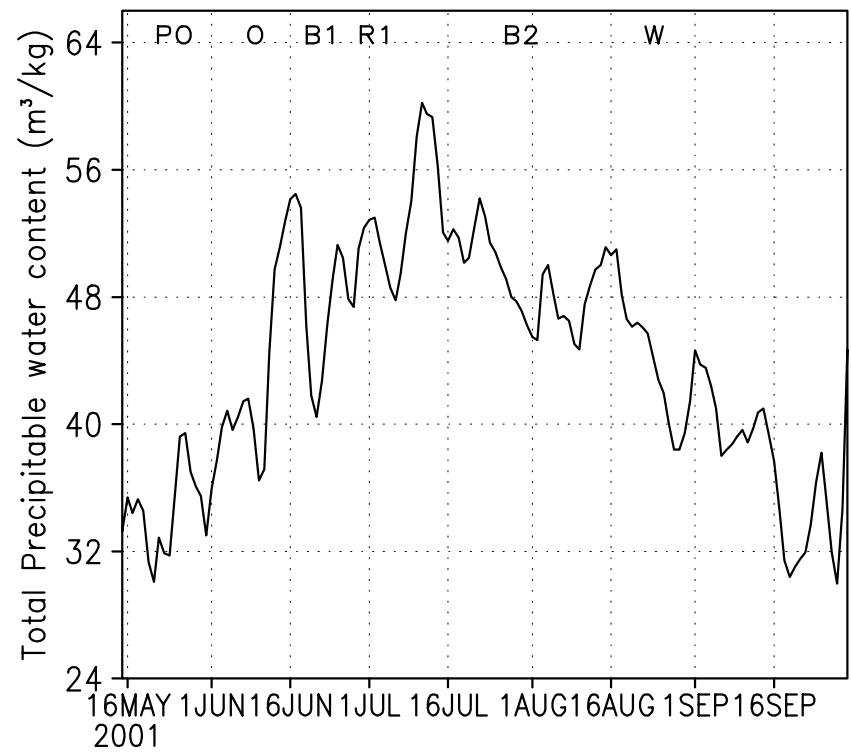

Figure 10. Daily total precipitable water content $\left(\mathrm{m}^{3} / \mathrm{kg}\right)$, period 15 May to 30 September 2001.

That is not easily modulated from the passage of weaker disturbances such as monsoon lows. The passages of a deep tropospheric monsoon depression (Godbole 1977) seem to modulate the water content more easily. If we look at the oscillation of surface temperature, we do see somewhat higher frequency modulations on the scale of 4 to 5 days. That seems to occur from the modulation of net solar radiation and cloud cover variations that do not invoke large tropospheric up and down vertical overturnings. The peak in the total precipitable water (around $60 \mathrm{~kg} / \mathrm{m}^{2}$ ) is reached by around July 10, which was the period of heavy rains $(\gg 19 \mathrm{~mm} /$ day) over central India. Thereafter we see a gradual diminution of total precipitable water. A marked bi-weekly oscillation in the total precipitable water content continues throughout the season. Around the time of the withdrawal of monsoon rains over central India, August 20, the precipitable water is still around $45 \mathrm{~kg} / \mathrm{m}^{2}$. Thereafter the decline in its value continues reaching around $20 \mathrm{~kg} / \mathrm{m}^{2}$ by September 18. This large drop is related to the southward movement of the monsoon trough and the prevailing northwesterly lower tropospheric flow fields.

\subsection{Surface and $850 \mathrm{hPa}$ relative humidity}

Over northeastern India north of the $20^{\circ} \mathrm{N}$ the equatorial trough (low sea level pressure) is essentially a heat low in the preonset months of May and June. Surface temperatures prevail near $40^{\circ} \mathrm{C}$ in the afternoon hours and the surface humidity is around $50 \%$ and at $850 \mathrm{hPa}$ is around $60 \%$ (figure 11a, b). The low pressure of the heat low 


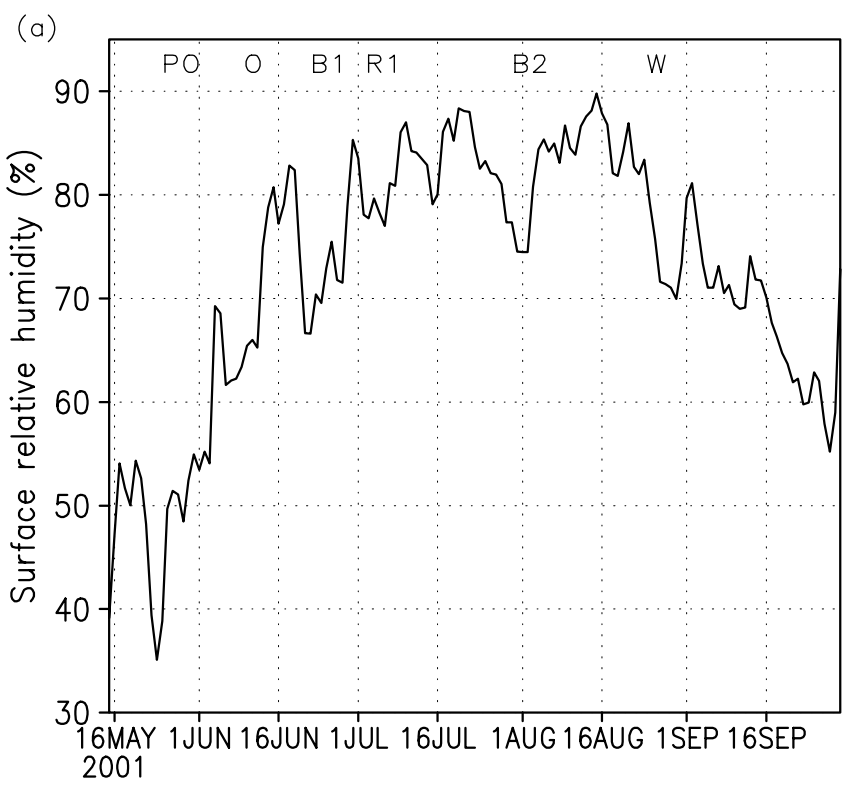

Figure 11(a). Daily relative humidity at surface (\%), period 15 May to 30 September 2001.

(b)

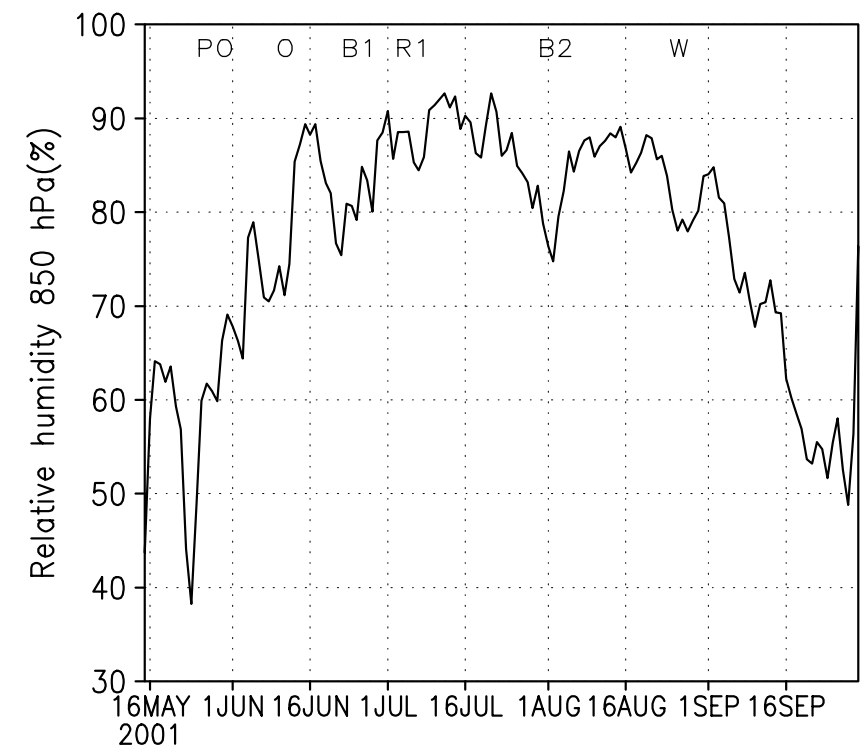

Figure 11(b). Daily relative humidity at $850 \mathrm{hPa}(\%)$, period 15 May to 30 September 2001.

carries a pressure gradient around it extending to the northern Bay of Bengal. That pressure gradient force plus the surface and PBL friction assist in a slow seepage of moist air from the Bay of Bengal (and even the Arabian Sea) into the heat low. The heat low gradually starts to moisten the eastern part of the monsoon trough and a plethora of shallow stratocumuli start advancing from the Bay towards the center of the heat low. The heat low soon acquires sufficient moist instability, and pre-monsoon thunderstorms start to prevail even before the onset date. As such moistening continues the heat low gradually transforms into a monsoon trough. This transformation of the heat low into a moist monsoon trough during early June is a characteristic feature of the onset of monsoon. The time evolution of relative humidity at the surface and the $850 \mathrm{hPa}$ level shows a more gradual rise (not abrupt as in the onset period). The surface humidity values after the onset reach values close to $70 \%$ and those at the $850 \mathrm{hPa}$ level reach values around $80 \%$. Some oscillation in the relative humidity values on the scale of 4 to 6 days match more those of the surface temperature fluctuations. A sharp drop in surface and $850 \mathrm{hPa}$ relative humidity, around August 1 was clearly related to the break B2 when the monsoon activity had moved to the foothills of the Himalayas and descending air prevailed over central India. Soon after the withdrawal of monsoon over central India the relative humidity at the surface and the $850 \mathrm{hPa}$ started decreasing and reached values close to $60 \%$, those values were close to $90 \%$ during the active spells of the monsoon.

\subsection{Dry and moist static stability}

Convection redistributes the moisture, which is central to our radiative transfer modeling. Dry and moist instabilities are basic elements of convection. The reanalysis data sets were used to compute the vertical variation of the dry and moist static energies $g z+C_{p} T$ and $g z+C_{p} T+L q$ respectively below the $700 \mathrm{hPa}$ level and the related dry and moist instabilities. That is shown in figure $12(\mathrm{a}, \mathrm{b})$ where an interesting inverse evolution for the dry and moist static stabilities is noted as one proceeds

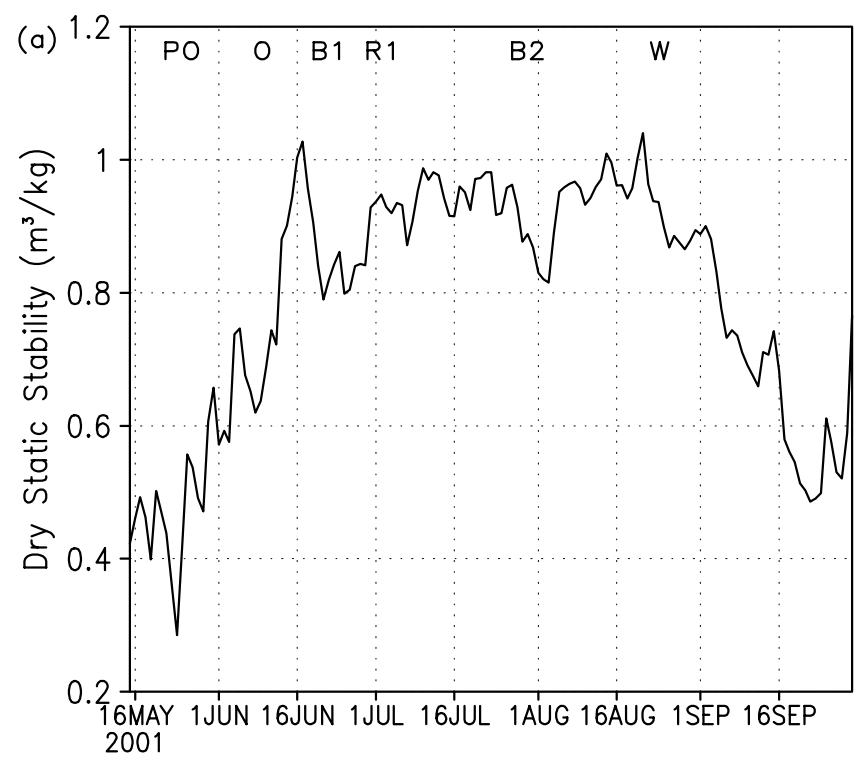

Figure 12(a). Daily dry static stability $\left(\mathrm{m}^{3} / \mathrm{kg}\right)$, period 15 May to 30 September 2001. 


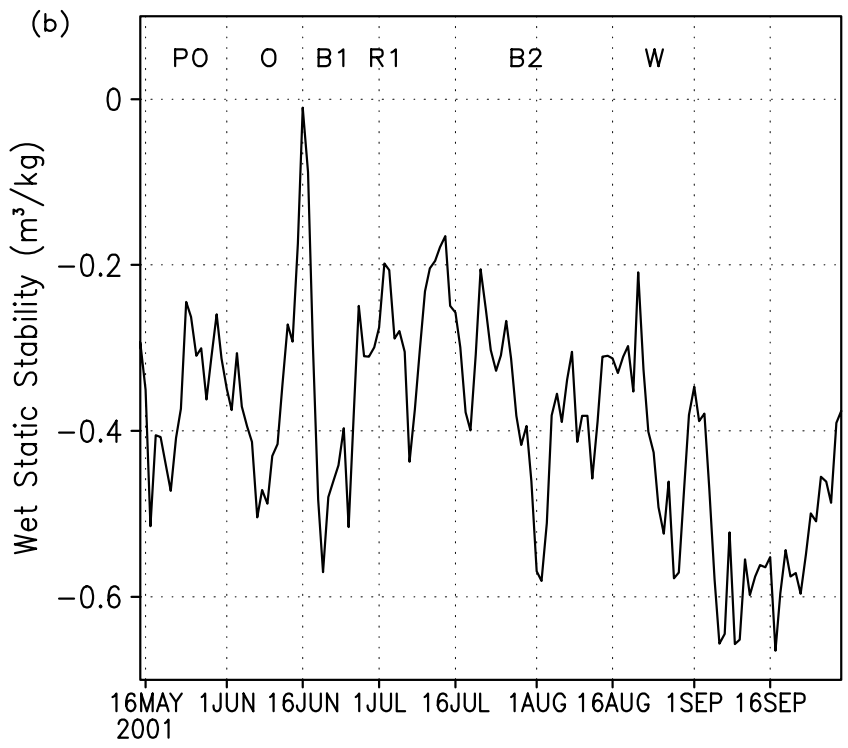

Figure 12(b). Daily wet static stability $\left(\mathrm{m}^{3} / \mathrm{kg}\right)$, period 15 May to 30 September 2001.

from the preonset to the postonset periods. The dry static stability has low values prior to the onset, i.e., around 0.3 to $0.5 \mathrm{~m}^{3} / \mathrm{kg}$, a gradual stabilization is noted after the onset with values going up to almost 0.8 to $1 \mathrm{~m}^{3} / \mathrm{kg}$. This figure also shows some oscillations in stability on the time scale of 4 to 6 days. The lowering of surface temperature contributes to this stabilization. The moist static stability exhibits large fluctuations between less unstable and unstable values throughout the monsoon season. The fluctuations reflect the frequent passage of monsoon lows and the more vigorous disturbances. During the preonset period values around -0.3 to $-0.5 \mathrm{~m}^{3} / \mathrm{kg}$ were noted. Around the time of the onset stabilization by clouds and rain contributed to a value close to 0 . Thereafter between dry and wet spells, the moist static stability fluctuates between values -0.5 and $-0.2 \mathrm{~m}^{3} / \mathrm{kg}$. The most interesting aspect of this illustration is clearly the cycle of stabilization and destabilization that is seen for moist static stability. A rapid decrease of dry static stability occurs soon after the withdrawal of monsoon rains. This is related to a slow increase of soil temperature from $27^{\circ} \mathrm{C}$ to around $29^{\circ} \mathrm{C}$, with an equivalent rise of air temperature. The mean moist static stability during the period between the onset and withdrawal is around $-0.3 \mathrm{~m}^{3} / \mathrm{kg}$. Soon after the withdrawal of monsoon rains a decrease of moisture content above the $850 \mathrm{hPa}$ level contributes to a moist destabilization and values as low as $-0.65 \mathrm{~m}^{3} / \mathrm{kg}$ start to prevail in September. This type of low value is also seen over the Bay of Bengal in this post monsoon period. The withdrawal of monsoon also goes with a diminution of tropospheric wind shear (easterly shear) and conditions slowly start becoming favorable for

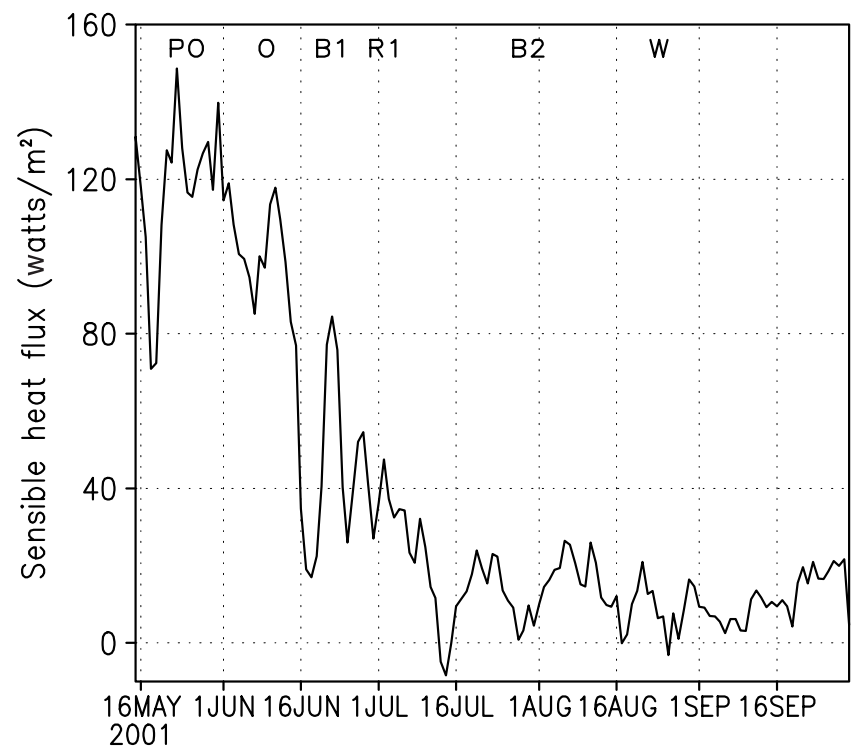

Figure 13. Daily sensible heat flux (watts $/ \mathrm{m}^{2}$ ), period 15 May to 30 September 2001.

tropical cyclone activity over the Bay. These stability fluctuations have overall implications on the generation of available potential energy over this monsoon domain. We have compared the temporal variations of dry and moist static instabilities. The former is largely affected by the passage of monsoon lows whose time scale is of the order of 4 to 5 days. The large changes in moist static stabilities are more on the time scale of 15 days that are largely the monsoon depressions affecting central India.

\subsection{Sensible heat fluxes}

The sensible heat fluxes from land areas in the reanalysis data sets invoke the surface similarity theory and the surface energy balance. These are complimented by a steady stream of 6 hourly surface and upper air data sets that undergo data assimilation as these fluxes are being continuously computed. Prior to the onset, with land surface temperatures reaching $35^{\circ} \mathrm{C}$ or higher (figure 4), the sensible heat fluxes over central India reach a value as high as 120 to 150 watts $/ \mathrm{m}^{2}$ (figure 13). Those are almost four times the oceanic values over the Bay of Bengal and the Arabian Sea during the summer season (Krishnamurti 1979). Subsequent to the onset, a sharp drop in the surface temperatures to $29^{\circ} \mathrm{C}$ is noted, these surface sensible heat fluxes show a marked drop towards values close to 30 watts $/ \mathrm{m}^{2}$. In fact the Bowen Ratio exceeds one prior to the onset and becomes much less than one after the onset of the monsoon. During the different phases of the monsoon the Bowen ratio changes from 13, 1.18, 0.8, 0.3, 0.06 
and 0.05 during preonset, onset, first break, first revival, second break and withdrawal respectively. The transition of the Bowen Ratio is a unique aspect of the onset of the monsoon over these semiarid land areas. A number of oscillations in the sensible flux were also noted. These oscillations were on the time scales of roughly 3 to 8 days. Prior to the onset these oscillations seem to be related to the Myanmar onset that sets in during the month of May. The passage of high clouds from the Myanmar monsoon modulates the surface temperature over India on these time scales thus impacting the sensible heating. Subsequent to the onset the high level clouds are more uniform over India and the amplitudes of the oscillations of the sensible heat get much smaller as the land surface temperature drops. During the break and active spells the value of sensible heat flux remains around 10 watts $/ \mathrm{m}^{2}$. No perceptible immediate increase in sensible heat flux is seen during the withdrawal phase in late August and early September. This has to do with persistent cloud cover that limits a rapid increase of ground temperature and furthermore we are already in September with the southward movement of the overhead sun and seasonal lower ground temperatures.

\subsection{Latent heat flux}

The transition of surface latent heat fluxes over the land area of the monsoon is generally opposite to that of the sensible heat fluxes. In the preonset phase the semi-arid land has latent heat fluxes of the order of $10 \mathrm{w} / \mathrm{m}^{2}$ and subsequent to the onset those values increase to as much as $100-150 \mathrm{w} / \mathrm{m}^{2}$ (figure 14). These postonset values are about one-half of the typical values of latent heat flux over the Bay of Bengal during the summer monsoon season. In this postonset we note some fluctuations in the latent heat flux that are roughly on the time scale of 4 to 5 days. These are related to the passage of monsoon lows. We have noted that just the increased cloud cover, from the passage of these lows, reduces the surface temperature and the sensible and the latent heat fluxes. These large fluxes values during the postonset contribute to a five-fold increase of soil moisture and roughly a $20 \%$ augmentation of the local precipitation budget from the recycling of the water from local evaporation. These are important aspects of the postonset surface hydrology. In the withdrawal phase we do see a marked drop in the latent heat fluxes during September. Values that had peaked to around 170 watts $/ \mathrm{m}^{2}$ drop to around 120 watts $/ \mathrm{m}^{2}$ in September. This is related to the relative lack of precipitation

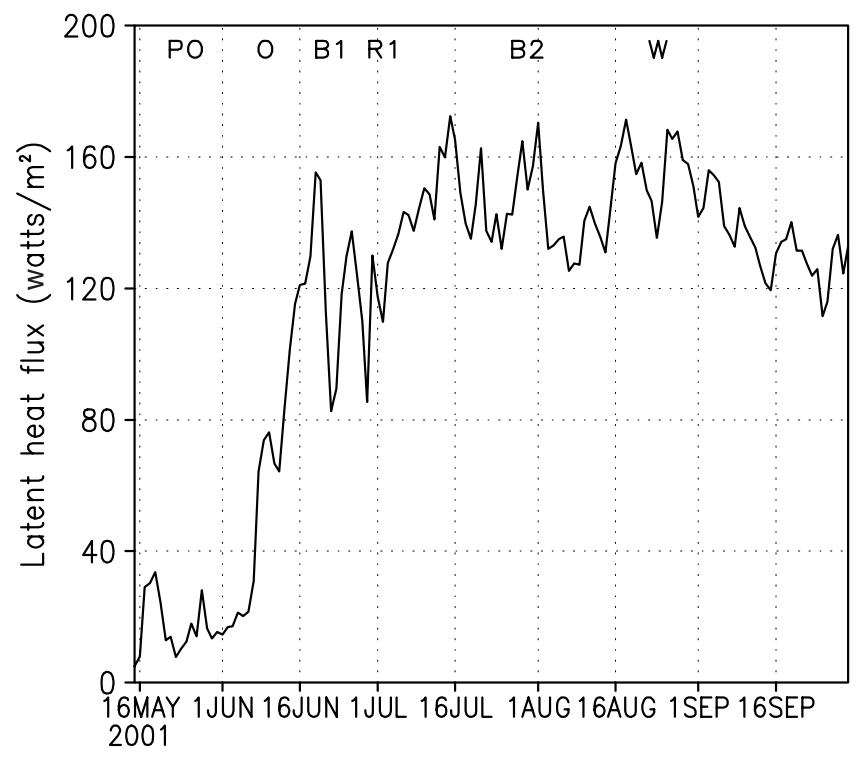

Figure 14. Daily latent heat flux $\left(\right.$ watts $\left./ \mathrm{m}^{2}\right)$, period 15 May to 30 September 2001.

over the central Indian domain after around August 18.

We shall next address the components of surface radiation during the transition of the monsoon. In the following section, on the elements of surface radiation, we have averaged the values geographically over the domain of figure 1 and present 24-hour averages. We cover the period 15 May to 30 September, 2001.

\subsection{Downward short wave radiation at the top of the atmosphere}

That is a simple curve of seasonal evolution of solar radiation at the top of the atmosphere, which peaks on June 18 at the latitudes of the central India box figure (1). The 24-hour averaged value of maximum radiation is around $470 \mathrm{watts} / \mathrm{m}^{2}$ at around the time of onset of rains (figure 15). By late September the solar radiation at the earth's surface has dropped to around 385 watts $/ \mathrm{m}^{2}$ as we move in the season.

\subsection{Downward short wave radiation at the earth's surface}

Figure 16 illustrates the downward short wave radiation (watts $/ \mathrm{m}^{2}$ ) at the earth's surface. The downward directed short wave radiation starts out with values averaged around 300 watts $/ \mathrm{m}^{2}$ prior to the onset of the monsoon. The striking feature here is the oscillations on the time scales of the monsoon lows and monsoon depressions. During a very active spell the heavy cloud cover reduces these fluxes to values as low as around 230 watts $/ \mathrm{m}^{2}$. 


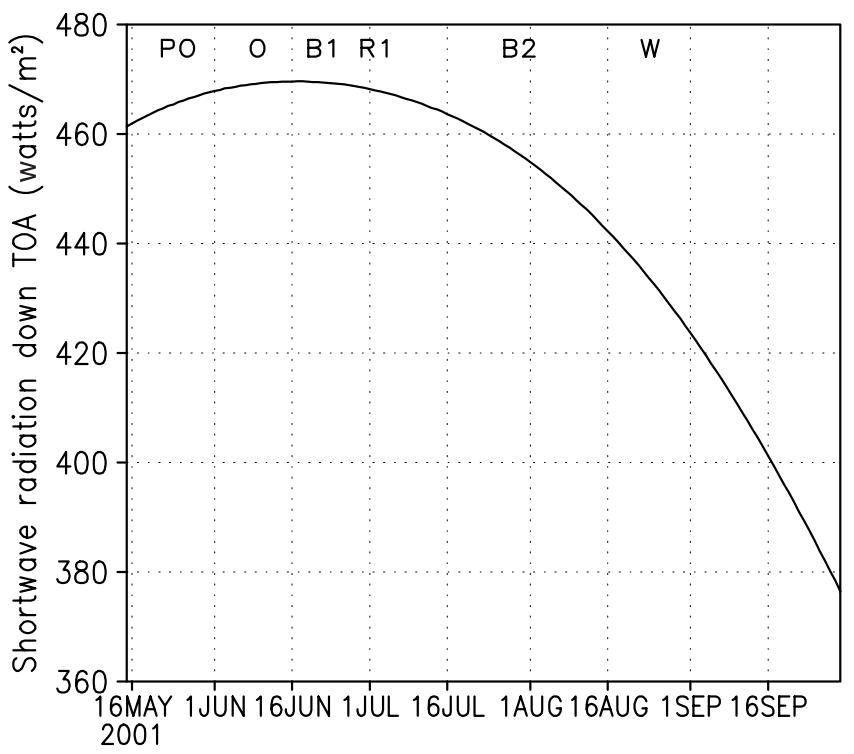

Figure 15. Daily downward short wave radiation at the top of atmosphere (watts $/ \mathrm{m}^{2}$ ), covering the period 15 May to 30 September 2001.

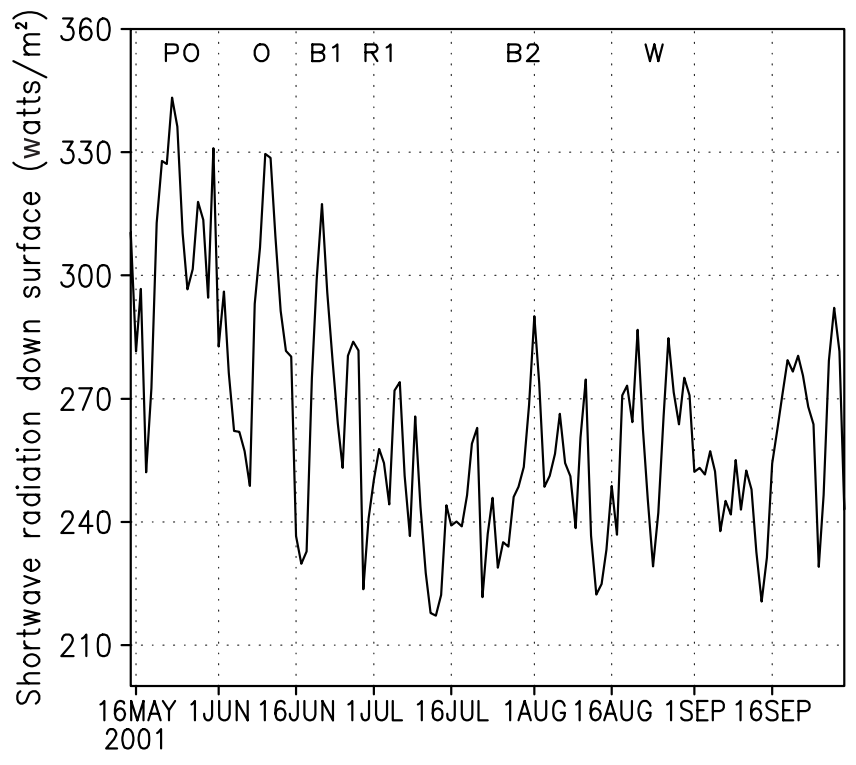

Figure 16. Daily downward short wave radiation at surface (watts $/ \mathrm{m}^{2}$ ) covering the period 15 May to 30 September 2001.

During the major break in the monsoon rain around August 1, 2001, the values rise to around $290 \mathrm{watts} / \mathrm{m}^{2}$. There is roughly a $50 \mathrm{watt} / \mathrm{m}^{2}$ oscillation in the downward flux of solar radiation at the earth's surface between active and break spells of the monsoon. These oscillations prevail through the withdrawal phase. Since monsoon activity continues in northern Bay, clouds prevail over the box of figure 1 from advection processes. The mean values of surface solar radiation during September are around 245 watts $/ \mathrm{m}^{2}$.

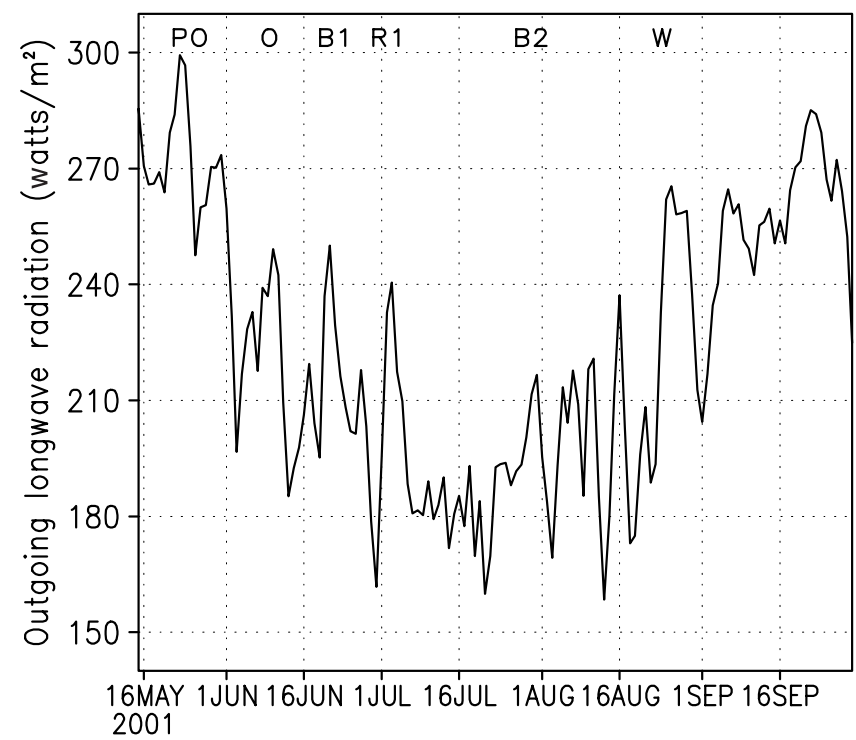

Figure 17. Daily outgoing long wave radiation (watts $/ \mathrm{m}^{2}$ ) covering the period 15 May to 30 September 2001.

\subsection{Reflected short wave radiation from the surface}

The short wave radiation reflected from the earth's surface is not presented here since that is simply $\alpha$ times the incoming short wave radiation at the earth's surface, where $\alpha$ is the surface albedo. We use a standard geographical distribution of albedo $\alpha$ for our study (Krishnamurti et al 1979) in calculating the reflected short wave radiation. The time history of reflected short wave radiation at the earth's surface is quite similar to that of the incoming solar radiation at the earth's surface. Albedo does show some time dependent changes as the semi-arid region becomes more green and moist, that is however not included in the present study. These big differences may be relevant over northwestern India where the albedo values are as large as $30 \%$. Over central India, those values are close to $12 \%$.

\subsection{Outgoing long wave radiation at the top of the atmosphere}

During the preonset period OLR values are as large as 280 to $300 \mathrm{watts} / \mathrm{m}^{2}$ (figure 17 ). Those values undergo a drop gradually in the preonset period due to the effects of the high cloud emanation from the Myanmar monsoon (that had its onset around May 15). As the monsoon goes through its active spells the outgoing long wave radiation (OLR) values drop to as low as 160 watts $/ \mathrm{m}^{2}$. A most striking feature is the temporal oscillation in OLR that shows no less than 25 peaks over a period of roughly 100 days. OLR seems to get modulated regularly from the passages of 


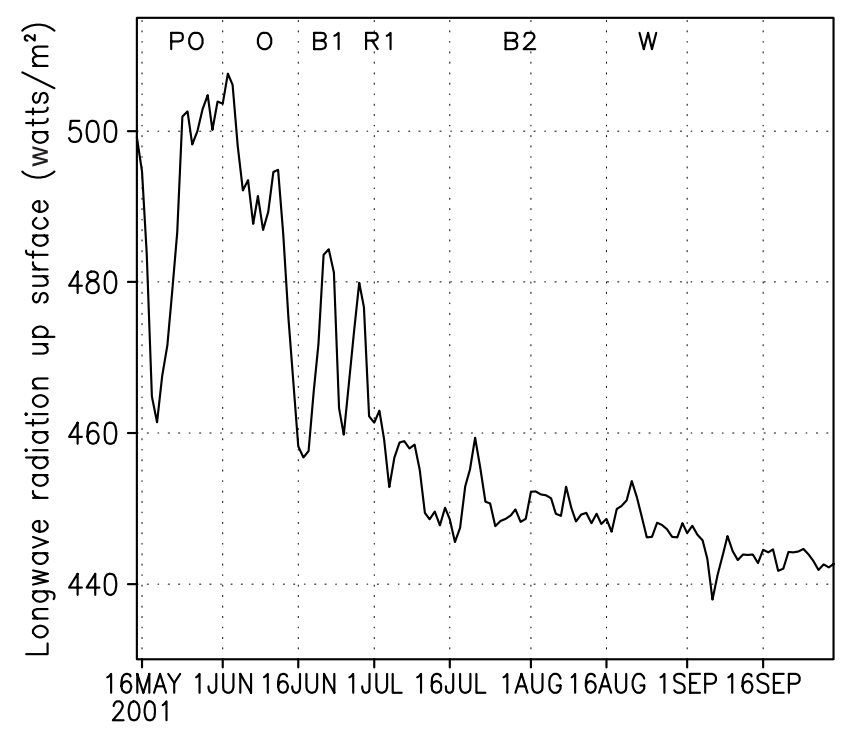

Figure 18. Daily upward long wave radiation at surface (watts $/ \mathrm{m}^{2}$ ) covering the period 15 May to 30 September 2001.

monsoon lows (and depressions). Monsoon lows form over the eastern half of the monsoon trough and traverse west northwestwards. They do influence the radiative heat balance of the central India box (figure 1) quite significantly. The amplitude of the OLR modulation by the monsoon lows is of the order of 50 to 70 watts $/ \mathrm{m}^{2}$. Subsequent to the withdrawal of monsoon rains over central India (around 16 August) a gradual rise in OLR values to almost 270 watts $/ \mathrm{m}^{2}$ by late August is noted. The 4 to 5 -day oscillation tends to continue during the withdrawal period. During late August and early September monsoon activity has not fully abated over the Bay of Bengal and outside the central India box in figure 1, those disturbances do influence the cloud cover fluctuations over the box.

\subsection{Upward long wave radiation at surface}

The upward long wave radiation from the earth's surface $\left(\sigma T_{g}^{4}\right)$ reflects the behavior of the ground temperature $\left(T_{g}\right)$. These values prior to the onset are around 510 watts $/ \mathrm{m}^{2}$ and in the postonset phase they drop to around 460 watts $/ \mathrm{m}^{2}$ (figure 18). A steep drop can be seen after the time of the onset, i.e., around The second week of June. The time history of the upward long wave radiation $\left(\overline{\sigma T_{g}^{4}}\right)$ is quite similar to that of the ground temperature $\left(\overline{T_{g}}\right)$. These two curves do not exactly match since the latter is an average ground temperature $\overline{T_{g}}$ over the box of figure 2, whereas the former is an average of $\sigma T_{g}^{4}$ over the box. The implied area averaging of nonlinearity contributes to some phase shift here. The value for the active and break phases of the monsoon are not that separated in

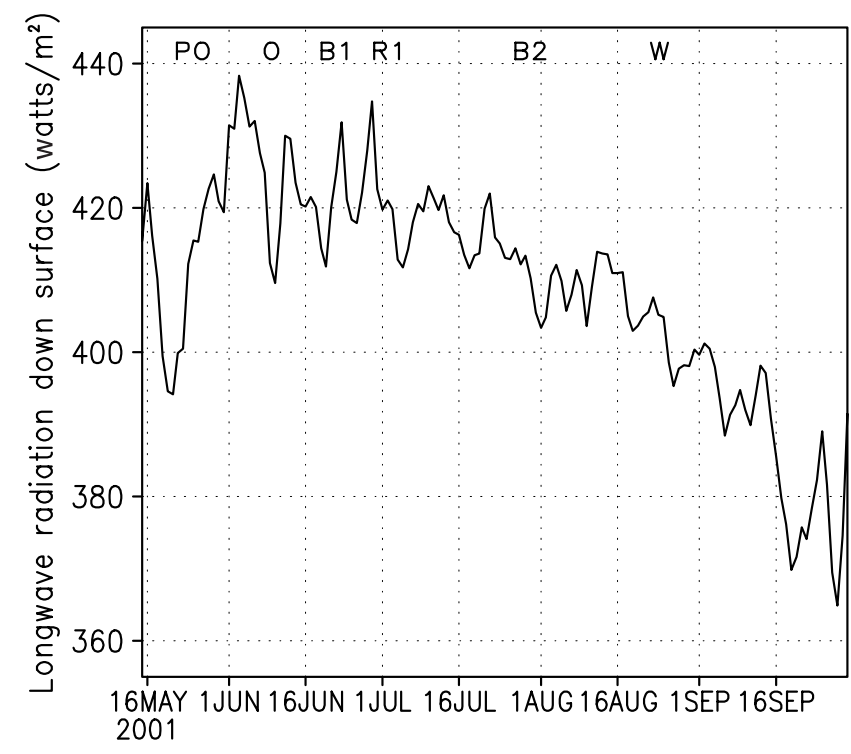

Figure 19. Daily downward long wave radiation at surface (watts $/ \mathrm{m}^{2}$ ) covering the period 15 May to 30 September 2001.

the upward long wave fluxes. After the withdrawal of the monsoon the averaged ground temperature exhibits a slow rise by about $1^{\circ} \mathrm{C}$ whereas the upward long wave radiation acquires a uniform value of around 443 watts $/ \mathrm{m}^{2}$, that difference is also attributed to the averaging of the nonlinear function $\overline{\sigma T_{g}^{4}}$. The over bar is an area average over the domain.

\subsection{Downward long wave radiation at the earth's surface}

The downward flux of long wave radiation at the earth's surface starts out with values around $420 \mathrm{watts} / \mathrm{m}^{2}$ during the preonset phase and continually drops to values around 380 watts $/ \mathrm{m}^{2}$ (figure 19). These values are most sensitive to the tropospheric moisture and cloud contents. Superimposed on this seasonal declining trend are oscillations on the time scale of monsoon disturbances and the amplitude of the oscillation are of the order of roughly 10 watts $/ \mathrm{m}^{2}$. One might wonder why the downward flux of long wave radiation is the largest in the preonset phase. After the onset of the monsoon there is a large absorption of long wave radiation by the increased moisture and clouds. These excess water and clouds absorb and remit the upward flux of long wave radiation from the ground. The ground temperature $T_{g}$ and the upward flux of long wave radiation from the earth's surface decreases after the onset. That decrease is infact a crucial element for the decrease of the downward flux of long wave radiation after the onset of the monsoon. This is an important aspect of the monsoonal surface radiation budget. 

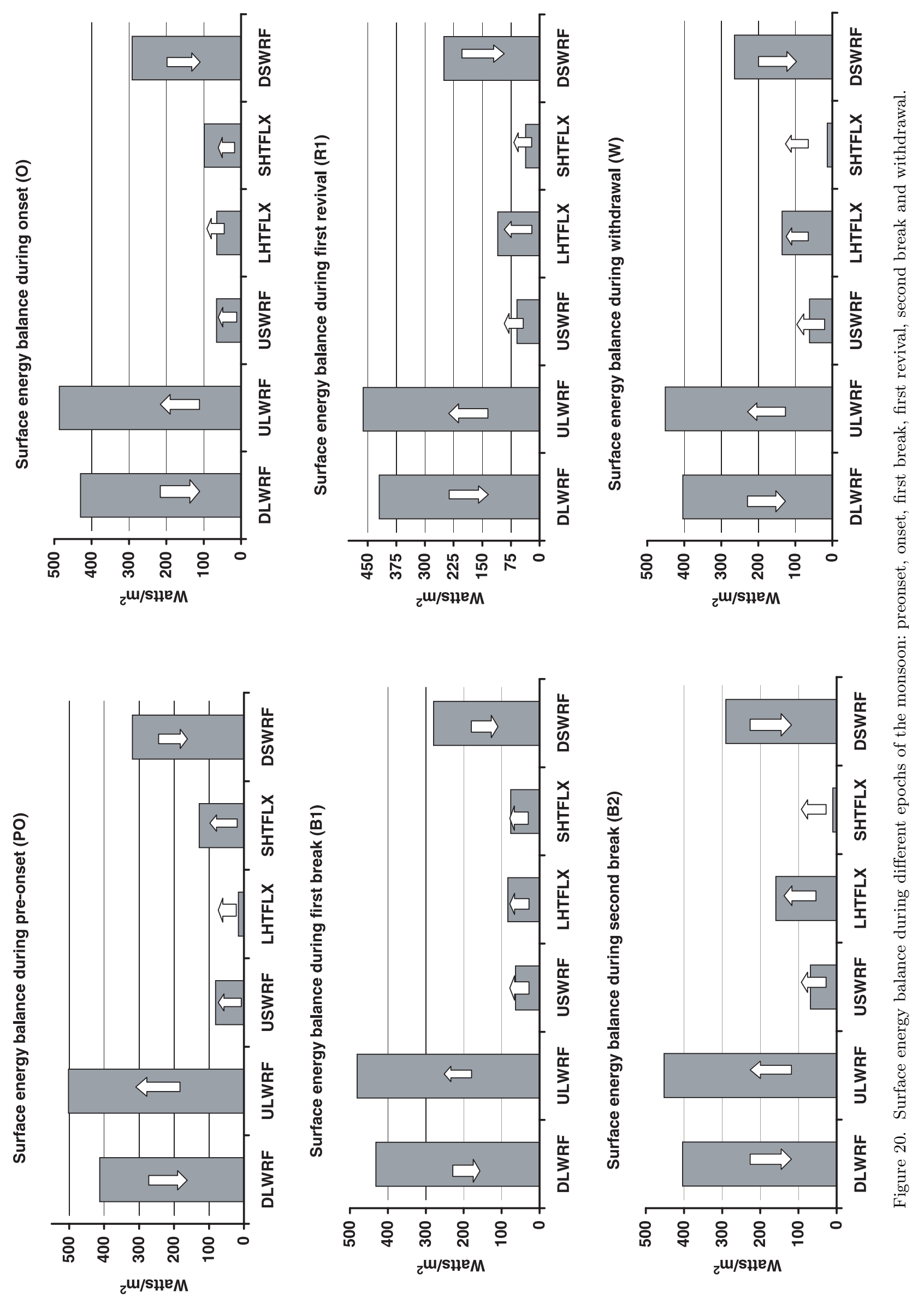
In most of the above diagrams we noted distinct oscillations in the surface energy parameters. We noted also that most of those oscillations were closely related in time to the passage of disturbances described earlier in reference to figure 5 .

\subsection{Surface energy balance diagrams}

The transitions of the surface energy balance can best be illustrated by taking a single day in the middle of these epochs of the monsoon (figure 20). With that in view we have taken a typical day during May to denote the preonset period and single days in the middle of the onset week, the first break, the revival, the second break and the withdrawal (around late August).

The major contributors to the downward directed fluxes during the life cycle of the monsoon are the short and long wave radiances. These are largely balanced by the upward directed long wave radiation $\left(501 \mathrm{watts} / \mathrm{m}^{2}\right.$ ) and the sensible heat flux $\left(128\right.$ watts $\left./ \mathrm{m}^{2}\right)$ prior to the onset of the monsoon rains. Around the onset period the clouds do cut down the downward directed short wave radiances by almost 20 watts $/ \mathrm{m}^{2}$. The balance at this stage is still largely arising from the upward flux of long wave radiation around 486 watts $/ \mathrm{m}^{2}$ (soil temperature still high $\approx 31^{\circ} \mathrm{C}$ ) and the sensible heat flux which is of the order of 99 watts $/ \mathrm{m}^{2}$. When the first break in monsoon rains is experienced the soil moisture had been slowly increasing and the latent heat flux has increased to almost 84 watts $/ \mathrm{m}^{2}$. That was very much smaller during the preonset and the onset phase. That plus the upward directed long wave radiation and the reflected short wave radiation contributes to most of the balance with respect to the downward directed short and long wave radiation. As the monsoon revives the largest contributors to the balance are the downward directed short $\left(250\right.$ watts $/ \mathrm{m}^{2}$ ) and long wave radiation (419 watts $/ \mathrm{m}^{2}$ ) and the upward directed long wave radiation (461 watts $/ \mathrm{m}^{2}$ ), the latent heat fluxes and the reflected short wave radiation. The latent heat has increased to roughly 110 watts $/ \mathrm{m}^{2}$. The radiative components continue to be the largest contributors among these. The upward flux of sensible heat continues around 36 watts $/ \mathrm{m}^{2}$ and is of the same order as the reflected short wave radiation. This is an active phase of the monsoon and all of the components seem to have some contribution towards the overall budget. When a late season major break in the monsoon occurred (around August 1) the sensible heat flux had abated with soil temperatures falling well below $29^{\circ} \mathrm{C}$. At this stage again the largest contributors to the overall balance come from downward directed short wave
( 290 watts $/ \mathrm{m}^{2}$ ) and the long wave ( 403 watts $/ \mathrm{m}^{2}$ ) radiation and the upward fluxes of latent heat and the long wave radiation $\left(452\right.$ watts $/ \mathrm{m}^{2}$ ) and the reflected short wave radiation. Finally we examined the withdrawal phase (around August 20 over central India) where we note a diminution of all components with the downward directed short wave radiation around 264 watts $/ \mathrm{m}^{2}$ (as compared to 319 watts $/ \mathrm{m}^{2}$ prior to the onset). The downward directed long wave radiation has a value of around 403 watts $/ \mathrm{m}^{2}$, which is close to its value prior to the onset. In this withdrawal phase the surface energy balance shows largely a balance among the upward flux of long wave radiation $\left(\approx 451\right.$ watts $\left./ \mathrm{m}^{2}\right)$ and the somewhat diminished latent heat flux of $135 \mathrm{watts} / \mathrm{m}^{2}$. Throughout the life cycle of the monsoon the reflected short wave radiation is an important contributor having values between 60 and 95 watts $/ \mathrm{m}^{2}$. This largely results from a surface albedo over central India of around $12 \%$. The story of the surface energy balance is a subtle one during the life cycle of the monsoon. Clearly the change in the components from one epoch of the monsoon to the next is a challenge for weather and climate modeling. It became clear from the analysis that moisture holdings of the atmosphere and clouds are key elements in these subtle changes of the energy budget. Those are the challenges for monsoon modeling.

\section{Conclusions}

The transitions that we portray in section 3.17 , all have a common theme. Tropospheric moisture and

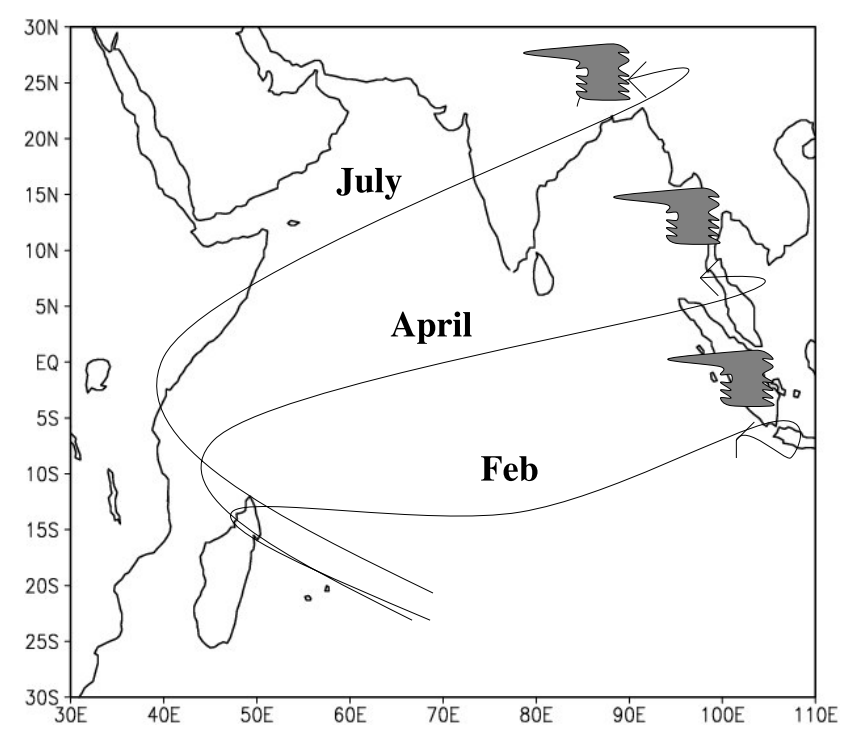

Figure 21. Monsoon gyre showing north/south migrating heat source. 
cloud radiative processes seem to play a very crucial role in these transitions. Climate forecasts for the monsoon region using singles and single cloud radiation schemes have experienced large errors in seasonal forecasts. We feel that we need ensemble and superensemble forecasts with multi models that explore and exploit this (tropospheric moisture and cloud) sensitivity to radiative processes. Modeling of the differential heating between heat sources and heat sinks of the monsoon is very sensitive to this overall radiation balance. During the annual cycle this differential heating is best portrayed by the principle axis of the monsoon which is a rain belt that migrates from Indonesia/northern Australia in January to the eastern foothills of the Himalayas in June. This rain belt starts retreating back from the foothills towards Indonesia in September. That heat source carries a monsoon trough in the lower troposphere and a thermal high in the upper troposphere. That axis draws moist air from the neighboring oceans, the familiar monsoon gyre (figure 21), is an atmospheric response to this north/south migrating heat source. The heat source along the principal axis contributes to a lowering of surface pressure resulting in an acceleration of zonal flows towards the low, shear flow instabilities and formation of monsoon disturbances followed by heavy rains. These disturbances tend to move northwestwards from the combined effects of steering from upper tropospheric easterlies and the beta effect. This contributes to the northwestward march of the monsoon onset isochrones. The southern flanks of these disturbances contribute to an enhancement of the basic moist southwest monsoon current bringing in the heavy rains. This background scenario of the monsoon carries a subtle surface energy balance in its seasonal history.

The total cloud cover is less than $40 \%$ prior to the onset, thereafter it fluctuates around $60 \% \pm 5 \%$ reflecting the dry and the wet spells quite nicely. It is interesting to note that the cloud cover during the withdrawal phase is still in excess of $45 \%$. That has to do with the intertropical convergence zone having moved to around $20^{\circ} \mathrm{N}$ and the associated clouds are still being advected westward by the upper troposphere easterlies. The surface evaporation shows an increase throughout the life cycle of the monsoon. It starts to decrease only at the withdrawal phase. During the preonset phase with the lowest soil moisture the evaporation rates are of the order of $0.3 \mathrm{~mm} /$ day, prior to the withdrawal the evaporation rates have reached values as high as $5.3 \mathrm{~mm} /$ day. What we see in figure 19 are subtle changes in the magnitudes of the components of surface energy balance during the life cycle of the Indian monsoon during one season. The differences among the net surface radiation (long and short wave incoming versus outgoing at the surface) are somewhat out of balance. These differences seem to be differentiating between the active and the inactive spells of the monsoon. Those are brought about from changes in cloud cover and moisture resulting in changes in the radiative transfer. The overall balance comes from the upward fluxes of sensible and latent heat and the reflected short wave radiation. Those also reflect large relative changes during the progress of the monsoon. All of these produce subtle changes in the thermodynamical variables and from one epoch of the monsoon to another. We also noted that the breaks in the monsoon do not immediately revert to preonset conditions. The gradual increase of soil moisture through the monsoon season makes the land surface quite different during breaks compared to the preonset. The retentivity of moisture in the soil makes many parameters such as relative humidity, latent heat flux, evaporation, sensible heat flux exhibit only smaller fluctuations between active and break spells compared to what we see between preonset and the subsequent active phases. Radiative transfer is a major part of the monsoon story. The large net short wave and long wave radiation at the earth's surface balance the sensible or the latent heat fluxes differently during different parts of the monsoon's life cycle. Careful modeling of the radiative components is clearly very important for the simulation of the seasonal cycle of the monsoon. Much further attention needs to be given to the moisture and cloud radiative processes for improvement of monsoon forecasts. Further extensions of this paper on cloud and moisture sensitivities for monsoon weather and seasonal climate forecasts covering several decades of data sets are underway.

\section{Acknowledgements}

Daily OLR data provided by the NOAACIRES Climate Diagnostics Center, Boulder, Colorado, USA USA, from their website at http://www.cdc.noaa.gov. This work is financially supported by NOAA grant: NA16GP1365, NSF grant: ATM-0419618 and NASA grant NAG513563.

\section{References}

Chen T C, Ren-Yow Tzeng and Ming-Cheng Yen 1988 Development and Life Cycle of the Indian Monsoon: Effect of the 30-50 Day Oscillation; Mon. Wea. Rev. 116 2183-2199.

Fels S B and Schwarzkopf M D 1975 The simplified exchange approximation: A new method for radiative transfer calculations; J. Atmos. Sci. 37 2265-2297. 
Godbole R V 1977 The composite structure of the monsoon depression; Tellus 29 25-40.

Harshvardhan, Randall D A, Corsetti T G and Dazlich D A 1989 Earth radiation budget and cloudiness simulation with a general circulation model; J. Atmos. Sci. 46 1922-1942.

Kalnay E et al 1996 "The NCEP/NCAR 40-year reanalysis project"; Bull. Amer. Meteor. Soc. 77 437-471.

Kistler R and Coauthors 2001 The NCEP/NCAR 50-year reanalysis: Monthly means CD-ROM and documentation. Bull. Amer. Meteor. Soc. 82 247-268.

Krishnamurti T N 1979 Compendium of Meteorology; WMO-No. 364, Geneva, Switzerland, WMO, 404-407 and $184-185$.

Krishnamurti T N, Pan H, Chang C B, Polshay J and Odally W 1979 Numerical Weather Prediction for GATE; Quart. J. Roy. Meteor. Soc. 105 979-1010.

Kummerow C D, Barnes W, Kozu T, Shiue J and Simpson J 1998 The Tropical Rainfall Measuring Mission (TRMM) Sensor Package; J. Atmos. Ocean. Tech. 15(3) 809-817.

Lacis A A and Hansen J E 1974 A parameterization for the absorption of solar radiation in the Earth's atmosphere; J. Atmos. Sci. 31 118-133.

Miyakoda K and Sirutis J 1986 Manual of the E-physics. [Available from Geophysical Fluid Dynamics Laboratory, Princeton University, P.O. Box 308, Princeton, NJ 08542.]
Pan H-L and Mahrt L 1987 Interaction between soil hydrology and boundary layer developments; Boundary Layer Meteor. 38 185-202.

Roberts R E, Selby J A and Biberman L M 1976 Infrared continuum absorption by atmospheric water vapor in the 8-12 micron window; Appl. Optics. 15 2085-2090.

Rodgers C D 1968 Some extension and applications of the new random model for molecular band transmission; Quart. J. Roy. Meteor. Soc. 94 99-102.

Sasamori T, London J and Hoyt D V 1972 Radiation budget of the Southern Hemisphere, in Meteorology of the Southern Hemisphere, Meteorological Monographs; American Meteorological Society 35 9-22.

Schwarzkopf M D and Fels S B 1985 Improvements to the algorithm for computing $\mathrm{CO}_{2}$ transmissivities and cooling rates; J. Geophys. Res. 90 10,541-10,550.

Schwarzkopf M D and Fels S B 1991 The simplified exchange method revisited: An accurate, rapid method for computation of infrared cooling rates and fluxes; J. Geophys. Res. 96 9075-9096.

Simon B and Joshi P C 1994 Determination of moisture changes prior to the onset of south-west monsoon over Kerala using NOAA TOVS satellite data; Meteor. Atmos. Phys. 53 223-231.

Thapliyal V, Majumdar A B and Krishnan V 2002 Weather in India - Monsoon Season (June to September 2001); Mausam 53 381-416. 